Original Article

\title{
ANALYTICAL METHOD VALIDATION, PHARMACOKINETICS AND BIOEQUIVALENCE STUDY OF DIMETHYL FUMARATE IN HEALTHY IRANIAN VOLUNTEERS
}

\author{
GHASEMIAN ELHAM ${ }^{1}$, SADRAI SIMA ${ }^{2}$, SHOKRI JAVAD ${ }^{3}$, SAYADI SHAHRAM ${ }^{4}$
}

1Department of Pharmaceutics, Faculty of Pharmacy, Islamic Azad University of Damghan, Damghan, Iran, ${ }^{2}$ Division of Biopharmaceutics and Pharmacokinetics, Department of Pharmaceutics, Faculty of Pharmacy, Tehran University of Medical Sciences, Tehran, Iran, ${ }^{3}$ Pharmaceutical department, Faculty of Pharmacy, Tabriz University of Medical Sciences, Tabriz, Iran, ${ }^{4}$ Anesthesiology Research Center, Shahid Beheshti University of Medical Sciences, Tehran, Iran Email: ghasemian_elham@yahoo.com

Received: 06 Jun 2021, Revised and Accepted: 31 Jul 2021

\section{ABSTRACT}

Objective: Pharmacokinetic evaluation of Dimethyl Fumarate (DMF) in the Iranian population wasn't studied. So, the aim of this research is the validation of the analytical method and evaluation of the pharmacokinetic properties and bioequivalence of the generic form of this drug versus the reference product.

Methods: 2 single-dose, test, and reference DMF products were orally administered to 24 healthy volunteers. The washout period was $28 \mathrm{~d}$ between the treatments. Monomethyl fumarate as the metabolite of DMF was analyzed by liquid chromatography-tandem mass spectrometry (LCMS/MS) and the method was validated. Also, the pharmacokinetic parameters were calculated for bioequivalence evaluation.

Results: The analytical method was validated and linear over the range of 31.25-4000 ng/ml ( $\left.\mathrm{R}^{2}=0.997\right)$. In addition, the method was precise and accurate in the low, medium, and high concentrations. The results indicated that the 2 products had similar pharmacokinetics. Further, the $90 \% \mathrm{CI}$ of the mean ratios of the test versus the reference products of the log-transformed area under the concentration-time curve over $10 \mathrm{~h}(0.99$ to 1.02$)$ and peak concentration ( 0.98 to 1.03 ) were within the acceptable range of 0.8 to 1.25 and the generic product of DMF could be similar to that of the reference product.

Conclusion: The applied analytical method is selective, accurate, precise, and repeatable for the analysis of monomethyl fumarate (MMF) in plasma. Also, the bioequivalence study showed no significant difference between the pharmacokinetic parameters of these 2 products. So, the DMF test product can be claimed to be bioequivalent with the reference product.

Keywords: Bioequivalent, Pharmacokinetics, Multiple sclerosis, Dimethyl fumarate, LC-MS/MS

(C) 2021 The Authors. Published by Innovare Academic Sciences Pvt Ltd. This is an open access article under the CC BY license (https://creativecommons.org/licenses/by/4.0/) DOI: https://dx.doi.org/10.22159/ijpps.2021v13i9.42328. Journal homepage: https://innovareacademics.in/journals/index.php/ijpps.

\section{INTRODUCTION}

Multiple sclerosis (MS) is a chronic autoimmune, inflammatory neurological disease of the central nervous system (CNS) [1] that attacks and destroyed the myelinated axons [2]. Most of the MS patients (80-85\%) have a Relapsing-Remitting Multiple Sclerosis (RRMS) disease form [3]. Treatment options in RRMS have increased to a dozen different available disease-modifying medicines and a few more are expected to be marketed soon [4].

Dimethyl fumarate (DMF), also known as BG-12, is the first-line oral treatment for RRMS [5] and has immunomodulatory properties [6]. DMF was approved for the treatment of psoriasis in 1959 [7] and got approved under the brand name of Tecfidera ${ }^{\circledR}$ for the treatment of RRMS in 2013 [8]. DMF may cause anti-inflammatory and cytoprotective activities that are mediated by the nuclear factor (erythroid-derived 2)-like 2 (Nrf2) antioxidant response pathway [9].

DMF is rapidly metabolized in the gastrointestinal tract into the primary active metabolite monomethyl fumarate (MMF) [10]. For this reason, DMF is not detectable in plasma after oral administration, and pharmacokinetics measurements are based on MMF concentrations [11]. MMF is dose-proportional over with high inter-subject variability [12]. Protein binding and volume distribution of MMF are $27-45 \%$ and 53-73 L, respectively [13]. By attention to this note that DMF microtablets in the capsules have an enteric coating, absorption has a delay leaving the stomach [3]. So, The reported time to peak concentration $\left(\mathrm{T}_{\max }\right.$ ) of MMF after oral administration of Tecfidera ${ }^{\circledR}$ capsules is $2-2.5 \mathrm{~h}$ and the half-life of

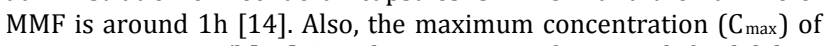
MMF was $1.87 \mathrm{mg} / \mathrm{l}$ [14]. An administration of DMF with food delays the time to reach the $\mathrm{C}_{\max }$ of MMF up to $5.5 \mathrm{~h}$ and causes a $40 \%$ decrease in $\mathrm{C}_{\max }$ but no effect on Area under the curve (AUC) [15].
Based on the above discussion, the current single-dose, 2-sequence, and crossover randomized study was designed to compare the bioequivalence of the Dimethyl fumarate formulation by Zistdaru Danesh Pharmaceutical Company (Teczifuma ${ }^{\circledR} 240 \mathrm{mg}$ ) as the test and Tecfidera ${ }^{\circledR} 240 \mathrm{mg}$ as the reference in 24 healthy Iranian (male/female) volunteers.

\section{MATERIALS AND METHODS}

\section{Subjects}

The protocol of this study was approved by the Ethics Committee of Islamic Azad university-Damghan branch, code: IR. IAU. DAMGHAN. REC.1398.004 and was registered in Iranian Registry Clinical Trials (IRCT), IRCT ID: IRCT20200623047902N1. Additionally, written informed consent was obtained from all volunteers before their enrollment. The enrolled volunteers included 14 healthy men and 10 healthy, non-pregnant women with a mean age of $34 \pm 5 \mathrm{y}$ (range of 23$43 \mathrm{y}$ ), a mean body weight of $75 \pm 18 \mathrm{~kg}$ (range of $47-110 \mathrm{~kg}$ ), and a mean height of $173 \pm 12 \mathrm{~cm}$ (ranging from 151 to $197 \mathrm{~cm}$ ). Based on the results of the completed clinical assessment, serum biochemistry, hematology, and routine urinalysis, all subjects were found to be healthy.

\section{Drug administration and sample collection}

The present single-dose, randomized, 2-treatment and 2-period crossover study was conducted on healthy Iranian male/female volunteers. The test or reference drug was randomly administered in a 1:1 ratio. In addition, all volunteers were fasted at least $10 \mathrm{~h}$ before drug administration up to $4 \mathrm{~h}$ after that. On the day of the test offered a single oral dose of reference and test formulations with $240 \mathrm{ml}$ of water. The washout period was $4 \mathrm{w}$. A total of 15 blood samples was collected before, $0.5,0.75,1,1.5,1.75,2,2.5,3,4,5,6,7$, 
8 , and $10 \mathrm{~h}$ after drug administration. A catheter was placed in an outer vein and blood samples were collected in tubes containing disodium-EDTA as an anticoagulant. The collected blood samples were then immediately centrifuged, and the plasma was separated and frozen at $-80{ }^{\circ} \mathrm{C}$ until analysis.

\section{Chemical}

Acetonitrile Pro HPLC (Merck), Zinc sulfate (Sigma), Methanol Pro HPLC (Merck), Formic Acid (Merck).

\section{Sample preparation}

To preparation of the standard solution, MMF stock solution $(50 \mu \mathrm{g} / \mathrm{ml})$ and plasma were spiked and mixed at 10: 490 for $2 \mathrm{~min}$. Then, the sample was kept without shaking for $10 \mathrm{~min}$. After that, the prepared content was vortexed for $5 \mathrm{~min}$. Then $50 \mu \mathrm{l}$ of zinc sulfate solution $(1.16$ M) and $450 \mu \mathrm{l}$ Acetonitrile were added to the solution. The sample was vortexed for $5 \mathrm{~min}$ and then held for $10 \mathrm{~min}$ without shaking. Then the sample was centrifuged at $15000 \mathrm{rpm}$ for $10 \mathrm{~min}$ and the upper phase was separated and injected into LC-MS/MS.

The intended standard plasma concentration range of 31.25-4000 $\mathrm{ng} / \mathrm{ml}$ was obtained through diluting the MMF standard solution $(400 \mu \mathrm{g} / \mathrm{ml})$.

\section{Chromatographic conditions}

Quadrupole mass spectrometer Quattro Micro (Waters-Micromass, UK) equipped with an electrospray source (Z-spray) was applied to conduct mass spectroscopy. Filtered samples were injected in a volume of $20 \mu \mathrm{L}$ into a Thermo $(50 \times 4.6 \mathrm{~mm}, 5$ microns $)$ column at $50{ }^{\circ} \mathrm{C}$ and separated by Alliance HT separations module 2795 (Waters, Milford, MA, USA), which consist of a quaternary solvent delivery system, degasser, Autosampler, column heater. Chromatographic separation was performed at a flow rate of 0.5 $\mathrm{ml} / \mathrm{min}$ using an elution buffer contains $85 \%$ of eluent A $(0.3 \%$ formic acid in water) and $15 \%$ eluent B (100\% methanol).

Mass spectrometry measurements were performed on Mass Lynx software, version 4.1. Samples were introduced to API positive source values as follows: Corona $1(\mathrm{uA})$; cone $25 \mathrm{~V}$; extractor, $1 \mathrm{~V}$; RF lens, $1 \mathrm{~V}$; Source temperature: $120^{\circ} \mathrm{C}$; Desolvation temperature: 400 ${ }^{\circ}$; Desolvation gas flow rate: $500 \mathrm{~L} / \mathrm{h}$ Cone gas (nitrogen $99.99 \%$ purity) flow rate: $150 \mathrm{~L} / \mathrm{h}$.

\section{Validation procedure}

Based on the Food and Drug Administration guidelines, the analytical method was validated in terms of linearity, range, specificity, accuracy, precision, and carryover [16].

\section{Specificity}

The Specificity test was conducted by comparing chromatograms of blank plasma, plasma spiked with $1 \mu \mathrm{g} / \mathrm{ml}$ monoethyl fumarate (MEF) as internal standard (IS) and, $31.25 \mathrm{ng} / \mathrm{ml} \mathrm{MMF}$ as the lower limit of quantification (LLOQ) [17].

\section{Linearity}

The spiked standard solutions of MMF (in the range of 31.25-4000 $\mathrm{ng} / \mathrm{ml})$ and MEF $(1 \mu \mathrm{g} / \mathrm{ml})$ as an internal standard in plasma were prepared and analyzed by LC-MS/MS system. The final calibration curves included three replicates per calibration concentration, and linearity was assessed by linear regression. The correlation coefficient of Linearity $\left(R^{2}\right)$ should be $\geq 0.98$.

\section{Accuracy and precision}

The precision and accuracy of the assay were determined from the low $(62.5 \mathrm{ng} / \mathrm{ml})$, medium $(500 \mathrm{ng} / \mathrm{ml})$, and high $(3000 \mathrm{ng} / \mathrm{ml})$ Quality Control (QC) plasma samples. The inter-day assay was determined by analyzing QC samples in triplicates and was analyzed on three different days. The intra-day precision and accuracy were determined for each QC sample in plasma, each in triplicate on one day (table 1). The precision determined at each concentration should not exceed $15 \%$ of the RSD\%, except for LLOQ $(31.25 \mathrm{ng} / \mathrm{ml})$ where it should not exceed $20 \%$ of the RSD $\%$ [18].

\section{Carryover effect}

During the method validation process of MMF, carryover was evaluated by injecting blanks, after previously injected sample with a concentration on Upper Level of Quantification (ULOQ) (3000 $\mathrm{ng} / \mathrm{ml}$ ).

Carryover on the blank should not be more than $20 \%$ of LLOQ and $5 \%$ for internal standards [19].

\section{Stability}

Stability studies were carried out according to EMEA guidelines. The medium concentration $(500 \mathrm{ng} / \mathrm{ml})$ of $\mathrm{MMF}$ in plasma was prepared in triplicates and kept frozen at $-80^{\circ} \mathrm{C}$ until analysis. For short-term stability tests one-hour thaw, freeze-thaw cycles were studied. One-hour stability was examined by leaving plasma quality control samples at room temperature on the bench one hour before preparation. Freeze-thaw stability of the samples was obtained over two freeze-thaw cycles, by thawing at room temperature and freezing for $12-24 \mathrm{~h}$ for each cycle respectively. The concentration of MMF after each storage period was compared with the initial concentration that was determined for samples that were freshly prepared and immediately processed. The mean area of the stability solution should be $\pm 15 \%$ of its freshly prepared solution [20].

\section{Pharmacokinetic analysis}

The standard non-compartmental procedure was applied to establish or calculate the pharmacokinetic parameters. Maximum plasma concentration $\left(\mathrm{C}_{\max }\right)$, time to reach the maximum plasma concentration $\left(\mathrm{T}_{\max }\right)$, area under the plasma concentration-time curve from time zero to the last measurable concentration $\left(\mathrm{AUC}_{0-\mathrm{t}}\right)$, and total area under the plasma concentration-time curve $\left(\mathrm{AUC}_{0 \text {-inf }}\right)$ were estimated from the plasma concentration-time data [21]. $\mathrm{C}_{\max }$ and $\mathrm{T}_{\max }$ were attained directly from the plasma data, while the $\mathrm{AUC}_{0 \text {-inf }}$ was calculated by adding the area from time zero to last sampling time, $t\left(\mathrm{AUC}_{0-\mathrm{t}}\right)$, and the area from time $\mathrm{t}$ to infinity $\left(\mathrm{AUC}_{\mathrm{t}}\right.$ $\left.{ }_{\mathrm{inf}}\right) . \mathrm{AUC}_{0-\mathrm{t}}$ was calculated using the trapezoidal formula, and; $A U \mathrm{C}_{\mathrm{t}-\mathrm{inf}}$ was calculated by dividing the last measurable plasma drug concentration $\left(\mathrm{C}_{\mathrm{t}}\right)$ with the elimination rate constant $\left(\mathrm{k}_{\mathrm{e}}\right)$ [22-23].

\section{Statistical analysis}

The values of $\mathrm{C}_{\max }, \mathrm{AUC}_{0-\mathrm{t}}, \mathrm{AUC}_{0 \text {-inf, }}$ and $\mathrm{T}_{\max }$ obtained with the two formulations were analyzed using the analysis of variance (ANOVA) procedure which differentiated effects due to subjects, periods, and treatments. Furthermore, $\mathrm{AUC}_{0-10}, \mathrm{AUC}_{0 \text {-inf, }}$ and $\mathrm{C}_{\max }$ were used as a base to evaluate the equivalence of the two formulations. The $90 \%$ $\mathrm{CI}$ of the test/reference mean ratios were determined for $\mathrm{C}_{\max }, \mathrm{AUC}_{0-}$ 10, and $\mathrm{AUC}_{0 \text {-inf. }}$ The applicable range of 0.8 to 1.25 can lead to the bioequivalence between the 2 formulations. The variations between the 2 compared parameters were statistically significant if the $\mathrm{P}$ values were less than 0.05 [24].

\section{RESULTS AND DISCUSSION}

\section{Analytical method validation \\ Specificity}

Under the chromatographic conditions described, MMF and the IS peaks were well resolved. Endogenous plasma components did not have any interfering peaks. Fig. 1 shows typical chromatograms of blank plasma as compare to spiked samples analyzed for a pharmacokinetic study. The average retention times of MMF and MEF were 6.2 and $2.4 \mathrm{~min}$, respectively.

\section{Linearity}

The calibration curve (fig. 2) was linear over the mentioned range. The LLOQ was $31.25 \mathrm{ng} / \mathrm{ml}$. The linearity of this method was statistically confirmed. For each calibration curve, the intercept wasn't statistically different from zero. The correlation coefficients $\left(\mathrm{R}^{2}\right)$ for calibration curves were adequate to or better than 0.997 . The calibration equation is $\mathrm{Y}=0.00154179 \mathrm{X}-0.0135467$. 


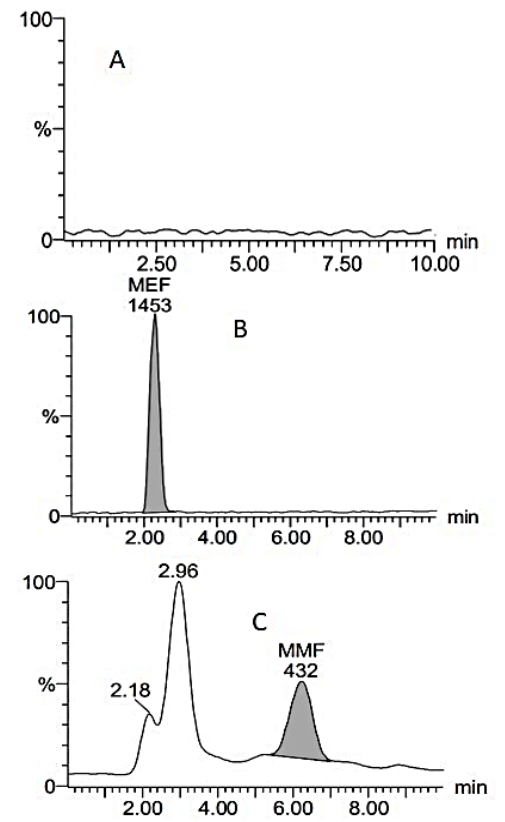

Fig. 1: Chromatograms of (A) blank plasma; (B) blank plasma spiked with $1 \mu \mathrm{g} / \mathrm{ml}$ MEF (IS) and (C) blank plasma spiked with $31.25 \mathrm{ng} / \mathrm{ml}$ MMF

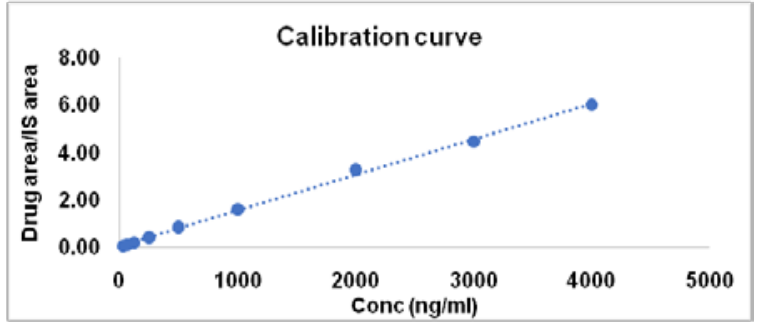

Fig. 2: Calibration curve of MMF in plasma

\section{Accuracy and precision}

The precision and accuracy of the assay were determined from the low $(62.5 \mathrm{ng} / \mathrm{ml})$, medium $(500 \mathrm{ng} / \mathrm{ml})$, and high $(3000 \mathrm{ng} / \mathrm{ml})$ Quality Control (QC) plasma samples. The inter-day assay was determined by analyzing QC samples in triplicates and was analyzed on three different days. The intra-day precision was determined for each QC sample in plasma, each in triplicate on one day (table 1). The both precision value (RSD \%) determined at each concentration wasn't more than $8.21 \%$.

Accuracy was expressed as the mean percentage of analyte that recovered in the assay. The results of the accuracy are shown in table 2. As shown, coefficients of variation were less than $10 \%$, which is acceptable for the routine measurement of the accuracy of the Bioanalytical method.

Table 1: Intra-day and inter-day precision of the method for determination of MMF in human plasma

\begin{tabular}{llll}
\hline & Concentration of MMF (ng/ml) & Average of drug area/IS area \pm SD & RSD\% \\
\hline Intra-day precision & 62.5 & $0.08 \pm 0.01$ & $0.73 \pm 0.03$ \\
& 500 & $4.37 \pm 008$ & 4.33 \\
Inter-day precision & 3000 & $0.08 \pm 0.00$ & 1.92 \\
& 62.5 & $0.75 \pm 0.00$ & 4.85 \\
& 500 & $4.42 \pm 0.09$ & 0.57 \\
\hline
\end{tabular}

Note: Data given in mean $\pm S D, n=3$

Table 2: Accuracy of the method for determination of MMF in human plasma

\begin{tabular}{lllll}
\hline & Concentration of MMF (ng/ml) & Average of drug area/IS area \pm SD & RSD\% & Deviation \\
\hline Intra-day Accuracy & 62.5 & $0.09 \pm 0.00$ & 4.23 & -9.51 \\
& 500 & $0.73 \pm 0.02$ & 2.73 & 3.44 \\
Inter-day Accuracy & 3000 & $4.37 \pm 0.10$ & 2.20 & 5.30 \\
& 62.5 & $0.09 \pm 0.00$ & 0.93 & -8.07 \\
& 500 & $0.77 \pm 0.06$ & 7.34 & -1.47 \\
\end{tabular}

Note: Data given in mean $\pm \mathrm{SD}, \mathrm{n}=3$
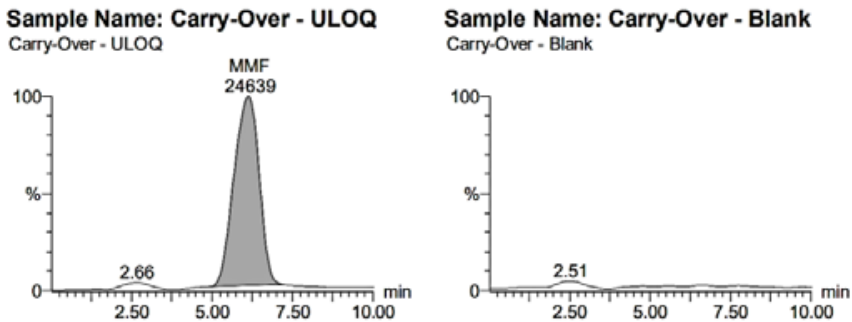

Fig. 3: Carryover effect between high concentration sample of MMF and blank

\section{Carryover effect}

Carryover between samples can occur in analytical methods. But in this method development carryover effect was evaluated and no accumulation after a high concentration of MMF was seen (fig. 3). So, it could be concluded no need for a meaningful cleaning procedure between injections.

\section{Stability}

The stability of MMF and IS in the short term and freeze and thaw cycles was tested. In all of these stability studies, both MMF and IS did not show any significant degradation (table 4). These results confirmed that MMF was stable in plasma under the storage conditions and during sample preparation. 
Table 4: Stability of MMF and IS in short term and freeze-thaw cycle

\begin{tabular}{|c|c|c|c|c|c|c|c|}
\hline & & \multicolumn{2}{|c|}{ Test (Area) } & \multicolumn{2}{|c|}{ Standard (Area) } & \multicolumn{2}{|c|}{ Test/STD mean ratio } \\
\hline & & MMF & IS & MMF & IS & MMF & IS \\
\hline \multirow{3}{*}{$\begin{array}{l}\text { Short term } \\
\text { stability }\end{array}$} & Mean & 3274.3 & 4215.3 & 2967.7 & 3875.3 & 1.1 & 1.1 \\
\hline & SD & 122.1 & 70.5 & 69.3 & 36.0 & & \\
\hline & RSD \% & 3.7 & 1.7 & 2.3 & 0.9 & & \\
\hline \multirow{3}{*}{$\begin{array}{l}\text { Freeze and thaw } \\
\text { stability }\end{array}$} & Mean & 3021.7 & 4215.3 & 2967.7 & 3875.3 & 1.0 & 1.1 \\
\hline & SD & 560.3 & 70.5 & 69.3 & 36.0 & & \\
\hline & $\mathrm{RSD} \%$ & 18.5 & 1.7 & 2.3 & 0.9 & & \\
\hline
\end{tabular}

Note: data given in mean $\pm S D, n=3$

As seen in the above table, there is less than a $10 \%$ difference between fresh standard and remained sample at room temperature for 1 hour and sample that passed 2 cycles of freezing and thawing.

\section{Pharmacokinetics}

35 subjects were screened. 24 subjects were randomized and included in the study. The subjects were divided into two groups according to the randomization table. There was one drop-out (Subject 20, because of fainting before drug administration of the second period). As a result, 23 subjects completed the study and no serious adverse effect was observed in any treatment. The pharmacokinetic parameters (mean $\pm \mathrm{SD}$ ) for the test and reference products are summarised in table 5. The logarithmic value of $\mathrm{C}_{\max }, \mathrm{AUC}_{0-10}$, and $\mathrm{AUC}_{0 \text {-inf means, }}$ ratios, and $90 \%$ CIs are summarised in table 6.

Table 5: Summary of pharmacokinetics parameters of test and reference

\begin{tabular}{|c|c|c|c|c|c|c|}
\hline Type & $\mathrm{C}_{\max }(\mathrm{ng} / \mathrm{ml})$ & $T_{\max }(\mathbf{h})$ & $K_{e}=-$ Slope $(1 / h)$ & $T_{1 / 2}=0.693 / k(h)$ & $\mathrm{AUC}_{0-10}(\mathrm{ng} . \mathrm{h} / \mathrm{ml})$ & $\operatorname{AUC}_{0 \text {-inf }}(\mathrm{ng} \cdot \mathrm{h} / \mathrm{ml})$ \\
\hline Test $(n=24)$ & $1689.9 \pm 716.1$ & $2.1 \pm 0.9$ & $1.1 \pm 0.2$ & $0.7 \pm 0.1$ & $3194.3 \pm 1308.3$ & $3225.3 \pm 1310.8$ \\
\hline Reference $(n=23)$ & $1863 \pm 1191$ & $2.5 \pm 0.9$ & $1.0 \pm 0.3$ & $0.8 \pm 0.3$ & $3200.2 \pm 1623.4$ & $3244.0 \pm 1621.6$ \\
\hline
\end{tabular}

Note: Data given in mean $\pm S D$, for Test $n=24$, for Reference $n=23$

Table 6: The logarithmic value of $\mathrm{C}_{\max }, \mathrm{AUC}_{0-10}$, and $\mathrm{AUC}_{0 \text {-inf }}$ means, ratios, and $90 \% \mathrm{CIs}$

\begin{tabular}{|c|c|c|c|c|c|c|}
\hline \multirow[t]{2}{*}{ Parameter } & \multirow[t]{2}{*}{ Formulation } & \multirow[t]{2}{*}{$\mathbf{N}$} & \multirow[t]{2}{*}{ mean \pm SD } & \multirow[t]{2}{*}{ Mean test/reference ratio \pm SD } & \multicolumn{2}{|c|}{ Confidence interval $90 \%$} \\
\hline & & & & & Lower & Upper \\
\hline \multirow[t]{2}{*}{$\mathrm{Ln} \mathrm{C}_{\max }(\mathrm{ng} / \mathrm{ml})$} & Test & 23 & $7.33 \pm 0.46$ & $1.00 \pm 0.07$ & 0.98 & 1.03 \\
\hline & Reference & 23 & $7.35 \pm 0.61$ & & & \\
\hline \multirow{2}{*}{ Ln $\mathrm{AUC}_{0-10}$ (ng. h/ml) } & Test & 23 & $7.98 \pm 0.45$ & $1.00 \pm 0.04$ & 0.99 & 1.02 \\
\hline & Reference & 23 & $7.96 \pm 0.46$ & & & \\
\hline \multirow[t]{2}{*}{ Ln $\mathrm{AUC}_{0 \text {-inf }}$ (ng. h/ml) } & Test & 23 & $7.99 \pm 0.44$ & $1.00 \pm 0.04$ & 0.99 & 1.01 \\
\hline & Reference & 23 & $7.98 \pm 0.46$ & & & \\
\hline \multirow[t]{2}{*}{$\mathrm{T}_{\max }(\mathrm{h})$} & Test & 23 & $2.1 \pm 0.9$ & $0.9 \pm 0.5$ & - & \\
\hline & Reference & 23 & $2.5 \pm 0.9$ & & & \\
\hline
\end{tabular}

Note: Data given in mean \pm SD, $n=23$

Average plasma concentration-time curves of test and reference products for a single dose of DMF are shown in fig. 4. The reference and test formulations used in the current study have mean AUC $_{0-10}$ values $3200.2 \pm 1623.4 \mathrm{ng} \cdot \mathrm{h} / \mathrm{ml}$ and $3194.2 \pm 1308.3$ $\mathrm{ng} \cdot \mathrm{h} / \mathrm{ml}$, respectively. Mean $\mathrm{C}_{\max }$ values for the reference and the test formulations are $1862.7 \pm 1191$ and $1686.9 \pm 716.1 \mathrm{ng} / \mathrm{ml}$, respectively. Further, the mean $\mathrm{T}_{\max }$ values were $2.5 \pm 0.9$ and $2.1 \pm 0.9 \mathrm{~h}$ in reference and test formulations (table 5). A higher inter-subject variability in $\mathrm{T}_{\max }$ was observed, which is as a result of variability in gastric emptying time delayed release capsules [25].

The results of the t-test, demonstrate no difference between the average parameters that resulted from sequencing, period, and administering the test and reference products at the significance level of 0.05 . The $90 \%$ CIs for the mean ratios of the test versus reference formulation of $\mathrm{C}_{\max }, \mathrm{AUC}_{0-10}$, and $\mathrm{AUC}_{0 \text {-inf }}$ equal to 0.98-1.03, 0.99-1.02, and $0.99-1.01$, respectively. Therefore, both are placed in an acceptable range of 0.80 to 1.25 and are found to be bioequivalent.

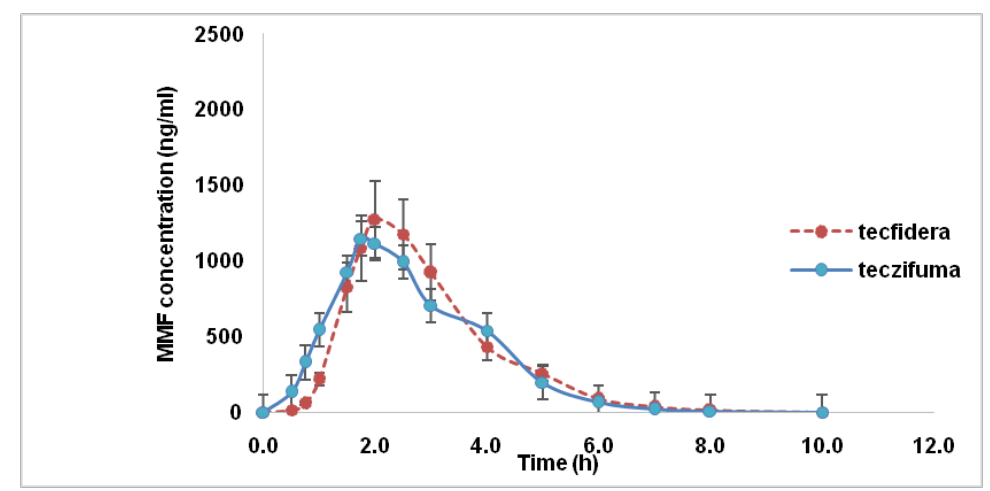

Fig. 4: MMF plasma concentration-time in healthy volunteers following consumption of Tecfidera ${ }^{\circledR} 240$ mg (reference) and Teczifuma ${ }^{\circledR}$ $240 \mathrm{mg}$ (test) $(\mathrm{n}=23)$. Concentration presented based on mean $\pm S D$ 


\section{CONCLUSION}

The optimized LC-MS/MS method is selective, accurate, precise, and repeatable. The method is linear over a wide range and utilizes a mobile phase that can be easily prepared. The run time is short and the protein precipitation technique is very simple. It can be concluded that the method is suitable for the routine quantification of MMF in human plasma.

Overall, in vivo examinations of the test and reference products revealed no significant difference between the pharmacokinetic parameters of these 2 products. Accordingly, the DMF test product can be claimed to be bioequivalent with the reference product and both products were similar in terms of the rate and extent of absorption. Therefore, considering that test product is pharmaceutical equivalent and bioequivalent, indicates that both products are therapeutically equivalent and interchangeable.

\section{ACKNOWLEDGEMENT}

We appreciate the Zistdaru Danesh Pharmaceutical Company for the financial support of this study.

\section{AUTHORS CONTRIBUTIONS}

All authors contributed to the practical work and writing of the manuscript. Sadrai and Ghasemian planned the study and collected blood samples and analyzed data and prepared manuscript. Shokri analyzed blood samples. Sayadi edited the manuscript. All authors wrote and revised the manuscript.

\section{CONFLICT OF INTERESTS}

The authors have declared that they have not any conflict of interest.

\section{REFERENCES}

1. Rouini MR, Dibaei M, Ghasemian E. Pharmacokinetics and bioequivalence studies of teriflunomide in healthy Iranian volunteers. Clin Pharmacol Drug Dev 2020;9:341-5.

2. Goldenberg MM. Multiple sclerosis review. PT 2012;37:175-84.

3. Burness CB, Deeks ED. Dimethyl fumarate: a review of its use in patients with relapsing-remitting multiple sclerosis. CNS Drugs 2014;28:373-87.

4. Ingwersen J, Aktas O, Hartung HP. Advances in and algorithms for the treatment of relapsing-remitting multiple sclerosis. Neurotherapeutics 2016;13:47-57.

5. Carlstrom KE, Ewing E, Granqvist M, Gyllenberg A, Aeinehband $\mathrm{S}$, Enoksson SL, et al. Therapeutic efficacy of dimethyl fumarate in relapsing-remitting multiple sclerosis associates with ROS pathway in monocytes. Nat Commun 2019;10:3081.

6. Foroughipour M, Gazeran S. Effectiveness and side effects of dimethyl fumarate in multiple sclerosis after 12 mo of follow up: an Iranian clinical trial. Iran J Neurol 2019;18:154-8.

7. Mills EA, Ogrodnik MA, Plave A, Mao Draayer Y. Emerging understanding of the mechanism of action for dimethyl fumarate in the treatment of multiple sclerosis. Front Neurol 2018;9:5.

8. Venci JV, Gandhi MA. Dimethyl fumarate (Tecfidera) a new oral agent for multiple sclerosis. Ann Pharmacother 2013;47:1697-702.

9. Fox RJ, Kita M, Cohan SL, Henson LJ, Zambrano J, Scannevin RH, et al. BG-12 (dimethyl fumarate): a review of mechanism of action, efficacy, and safety. Curr Med Res Opin 2014;30:251-62.

10. Cho H, Hartsock MJ, Xu Z, He M, Duh EJ. Monomethyl fumarate promotes Nrf2-dependent neuroprotection in retinal ischemiareperfusion. J Neuroinflammation 2015;12:239.
11. TECFIDERA ${ }^{\text {m"m }}$ (dimethyl fumarate) delayed-release capsules, for oral use, FDA approved labeling text; 2013.

12. Sheikh SI, Nestorov I, Russell H, O'Gorman J, Huang R, Milne GL, et al. Tolerability and pharmacokinetics of delayed-release dimethyl fumarate administered with and without aspirin in healthy volunteers. Clin Ther 2013;35:1582-94. e9.

13. Dubey D, Kieseier BC, Hartung HP, Hemmer B, Warnke C, Menge $\mathrm{T}$, et al. Dimethyl fumarate in relapsing-remitting multiple sclerosis: rationale, mechanisms of action, pharmacokinetics, efficacy and safety. Expert Rev Neurother 2015;15:339-46.

14. Tecfidera $240 \mathrm{mg}$ gastro-resistant hard capsules: Annex I: summary of product characteristics. Available from: https://www.ema.europa.eu/en/documents/productinformation/tecfidera-epar-product-information_en.pdf. [Last accessed on 02 May 2021].

15. Thomas RH, Wakefield RA. Oral disease-modifying therapies for relapsing-remitting multiple sclerosis. Am J Health Syst Pharm 2015;72:25-38.

16. Bioanalytical Method Validation Guidance for Industry. Food and Drug Administration, Center for Drug Evaluation and Research (CDER), USA; 2018. Available from: https://www.fda.gov/ files/drugs/published/Bioanalytical-Method-ValidationGuidance-for-Industry.pdf. [Last accessed on 02 May 2021]

17. Guidance for Industry Q2B Validation of Analytical Procedures: Methodology. Geneva; 1996. Available from: https:// www.fda.gov/media/71725/download.[Last accessed on 02 May 2021]

18. Tijare LK, Rangari NT, Mahajan UN. A review on bioanalytical method development and validation. Asian J Pharm Clin Res 2016;9 (Suppl 3):6-10.

19. Wenkui L, Ying HL, Austin C, Shaolin Z, Weng N. Simultaneous determination of norethindrone and Ethinyl estradiol in human plasma by high-performance liquid chromatography with tandem mass spectrometry-experience on developing a highly selective method using derivatization reagent for enhancing sensitivity. J Chromatogr B: Anal Technol Biomed Life Sci 2005;825:223-32.

20. Adluri P, Kumar YS. Development and validation of sensitive LC-ESI-MS/MS method for the simultaneous estimation of dapagliflozine and saxagliptin in human plasma. Int J Pharm Pharm Sci 2019;11:55-9.

21. Harahap Y, Malia CD, Sunarish. Pharmacokinetic profile of metformin hydrochloride in dried blood spot of healthy subjects using high performance liquid chromatographyphotodiode assay. Int J Appl Pharm 2018;10:354-7.

22. Design and Analysis of Bioavailability and Bioequivalence Studies. $2^{\text {nd }}$ ed. Revised and Expanded. Shein-Chung Chow and Jen-Pei Liu; 2000.

23. Guidance for Industry. Bioavailability and Bioequivalence Studies for Orally Administered Drug Products-General Considerations. U. S. Department of Health and Human Services. Food and Drug Administration. Center for Drug Evaluation and Research (CDER); 2003.

24. Drug control division, Food and drug administration, Ministry of Public Health, Thailand. Guideline for the conduct of bioavailability and bioequivalence studies; 2009 .

25. Lategan TW, Wang L, Sprague TN, Rousseau FS. Pharmacokinetics and bioavailability of monomethyl fumarate following a single oral dose of bafertam ${ }^{\mathrm{m}}$ (Monomethyl Fumarate) or Tecfdera ${ }^{\circledR}$ (Dimethyl Fumarate). CNS Drugs 2021;35:567-74. 